\title{
PÓS-GRADUAÇÃO STRICTU SENSU E DESENVOLVIMENTO REGIONAL
}

\section{STRICTUSENSU POST-GRADUATION AND DEVELOPMENT REGIONAL}

\author{
Maria da Conceição Fonseca-Silva ${ }^{1}$ \\ Recebido para publicação em 17/11/2007 \\ Aceito para publicação em 02/03/2008
}

\section{RESUMO}

O processo de desenvolvimento regional depende do estabelecimento de políticas específicas para as regiões. A criação e consolidação de cursos de pósgraduação Strictu Sensu são fatores fundamentais para a formação de cidadãos críticos, com habilidades e competências para intervir afirmativamente nos processos sociais e políticos locais e regionais. O sistema de pós-graduação no Brasil é nacional, mas deve contemplar diferenças e especificidades regionais. Considerando, pois, a importância da regionalização da política de pós-graduação e a necessidade de criar programas temáticos e multidisciplinares que respondam às especificações e vocações da região nordeste e, especificamente, da região do sudoeste da Bahia, foi criado e implantado, na Universidade do Sudoeste da Bahia, o Mestrado em Memória: Linguagem e Sociedade.

Palavras-chave: Pós-Graduação Strictu Sensu; Desenvolvimento regional; Mestrado em Memória: Linguagem e Sociedade.

\begin{abstract}
The regional development process depends upon the establishment of specific politics for the regions. The creation and consolidation of Strictu Sensu PostGraduation Courses constitute fundamental factors for the formation of critic citizens, with abilities and competences to act affirmatively in the social and political local and regional processes. The Post-Graduation system in Brazil is national, but it should be able to contemplate regional differences and specificities. Considering the importance of regionalization of Post-Graduation politics and the necessity to create thematic and multidisciplinary programs capable of answering the specificities and vocations of Northeast Region and, specifically, of Southeast of Bahia, it was created and implanted at the University of Southwest of Bahia, the Masters in Memory: Language and Society.
\end{abstract}

Key words: Strictu Sensu post-graduation; Development regional; Master Degree in Memory: Language and Society.

\footnotetext{
${ }^{1}$ Doutora em Lingüística pela Unicamp. Professora de Lingüística e de Análise de Discurso do Departamento de Estudos Lingüísticos e Literários da Universidade Estadual do Sudoeste da Bahia - Uesb. Coordenadora do mestrado em Memória: Linguagem e Sociedade, na mesma universidade. con.fonseca@gmail.com
} 


\section{Considerações gerais}

O ensino superior no Brasil teve início em conseqüência da necessidade de quadros profissionais que pudessem servir à Corte recém chegada ao País. Dessa forma, somente a partir de 1808, com a vinda da família Real Portuguesa, foram criadas as primeiras escolas superiores, quais sejam: a Academia Real da Marinha, o curso de cirurgia na Bahia, o curso de cirurgia e anatomia no Rio de Janeiro e a Academia Real Militar. No período do Império, foram criadas a Faculdade de Direito de São Paulo, a Faculdade de Direito de Recife, a Faculdade de Medicina do Rio de Janeiro, a Faculdade de Medicina na Bahia, a Escola Politécnica no Rio de Janeiro e a Escola de Minas de Ouro Preto. Conforme (FERREIRA E MOREIRA, 2001), nos primeiros anos da República, o país registrava 24 escolas. Entre 1890 e 1930, surgiram oito faculdades de engenharia e dezessete faculdades de direito. Pela ligação com a Igreja, essas instituições tinham como modelo o ensino profissionalizante direcionado tanto para a política quanto para a administração pública.

Em decorrência dos movimentos em prol da educação, o Brasil assiste, em 1932, ao Manifesto dos Pioneiros da Educação que, assinado por educadores e escritores, recomendava a criação de universidades capazes de integrar as atividades de ensino e pesquisa. Surgiram as primeiras universidades institucionalizadas do País que simbolizaram um novo modelo de organização de ensino superior baseado em instituições mais orgânicas, integrando ensino e pesquisa e servindo de referência fundamental para experiências posteriores: em 1934, foi criada a Universidade de São Paulo (USP); e, em 1935, a já extinta Universidade do Distrito Federal.

Em 1948, foi criada a fundação da Sociedade Brasileira para o Progresso da Ciência (SBPC). Em 1951 foram criados, de um lado, o Conselho Nacional de Pesquisas, CNPq (hoje Conselho Nacional de Desenvolvimento Científico e Tecnológico) - a quem coube fomentar as atividades na área de energia nuclear e à pesquisa em geral, por meio tanto de concessão de auxílios para a manutenção de laboratórios quanto de concessão de bolsas de estudos para capacitar científica e tecnologicamente recursos humanos e organizar, com a comunidade científica, a carreira de pesquisador -; e, de outro lado, a Campanha de Aperfeiçoamento de Pessoal de Nível Superior, a Capes (atual Coordenação de Pessoal de Nível Superior), órgão responsável pela institucionalização e regulamentação da Pós-Graduação stricto sensu. Essas agências surgiram em decorrência da pressão e da persistência de grupos de pesquisadores da comunidade científica da época, muitos com contato com instituições e grupos de pesquisa internacionais. Além de marcarem o início da valorização do ensino superior, foram responsáveis pela implantação de políticas de pesquisa e da pósgraduação stricto sensu no país.

Em razão da necessidade de o Ministério da Educação implantar e desenvolver o regime de cursos de pós-graduação no ensino superior no Brasil, a pósgraduação teve sua definição em 1965, pelo Parecer C.E.Su. $n^{\circ}$. 977/65, elaborado por Sucupira (1965). No parecer, o autor defendia a necessidade de uma sistemática implantação dos cursos de pós-graduação no país, defendendo que ganhariam tanto o campo acadêmico científico quanto o campo da produção de tecnologia aplicável às necessidades industriais do desenvolvimento nacional. Além disso, argumentava que a pós-graduação iria conferir o caráter verdadeiramente universitário à universidade, ao assumir o papel imperativo de suprir a deficiência do sistema e de assegurar a capacitação de quadros docentes qualificados, de um lado; e ao estimular e assegurar o desenvolvimento da pesquisa, preparando adequadamente os pesquisadores e trabalhadores intelectuais no mais alto padrão para fazer face às necessidades do desenvolvimento nacional em todos os setores.

É interessante salientar que Sucupira (1965) defendia que fossem criados princípios doutrinários para a regulamentação da pós-graduação e também de padrões efetivos de avaliação, ou seja, de critérios operacionais e normas que dirigissem e controlassem sua implantação e desenvolvimento. O autor argumentava que o fato de uma instituição ter seus cursos de graduação reconhecidos não era suficiente e nem indicava que tal instituição estivesse habilitada para instituir a pós-graduação.

Ressaltamos que a pós-graduação, como observa Barros (1998), só foi formalmente implantada em 1968, a partir da reforma do ensino superior, pela 
Lei no. 5.540/68 (Lei de Reforma Universitária), que complementava e, ao mesmo tempo, redimensionava as disposições da Lei de Diretrizes e Bases da Educação (LDB, Lei no. 4.024/61). Em tal reforma, cabia à pós-graduação qualificar professores para o ensino superior, capacitar profissionais para atuar nos setores públicos e privado e estimular a produção de conhecimento científico vinculado ao desenvolvimento do país. Essa lei de reforma estabelecia, entre outras coisas, a indissociação do ensino e da pesquisa e a exigência de que o professor universitário deveria ter uma formação de pós-graduação no sentido stricto. As disposições da antiga LDB, Lei no. 4.024/61 e da Reforma Universitária, Lei 5.540/68 foram revogados pela atual LDB, Lei no. 9.394/96, que passou a estabelecer as diretrizes da educação no Brasil.

Apesar da revogação, a artigo 44 da Lei no. 9.394/96, inciso III, dispõe sobre pós-graduação e mantém a doutrina defendida no parecer CFE no. 977/ 65, endereçado à C.E.Su e elaborado por Sucupira (1965), que defendia princípios doutrinários para a regulamentação da pós-graduação e critérios operacionais e normas para controlar tanto a implantação quanto ao desenvolvimento dos programas de pós-graduação.

Os programas de pós-graduação stricto sensu passam desde meados da década de 70 do século XX por um rigoroso processo de avaliação pela CAPES, a quem cabe a sua aprovação para implantação, continuidade e crescimento. Daí que tem sido freqüente o fechamento de mestrados e doutorados no país que não atingem os níveis de excelência mínimos exigidos.

O número de programas de pós-graduação stricto sensu que constam na Avaliação Trienal 2007 da CAPES indica o avanço da pós-graduação no país, principalmente nas regiões e nas unidades da federação mais desenvolvidas, como pode ser observado nos gráficos 1 e 2 a seguir:

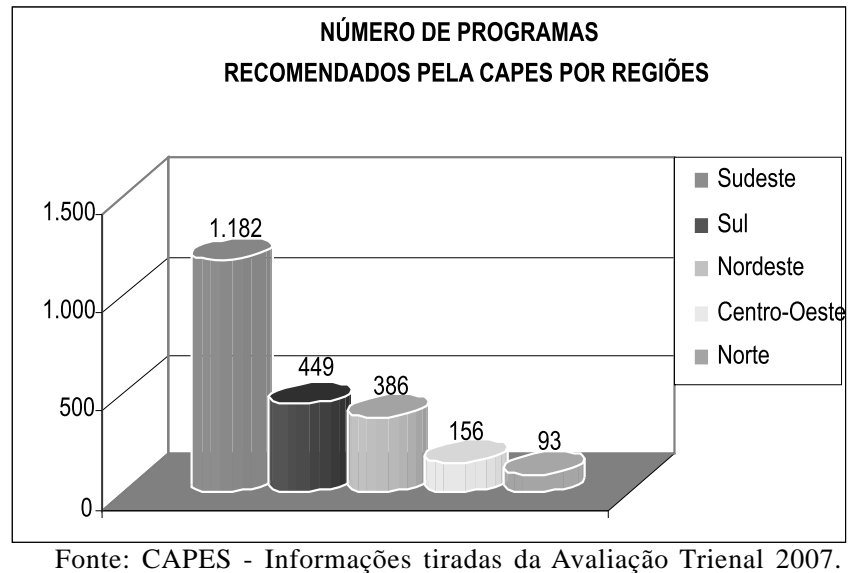

Gráfico 1 - Número de programas recomendados pela Capes por Regiões.

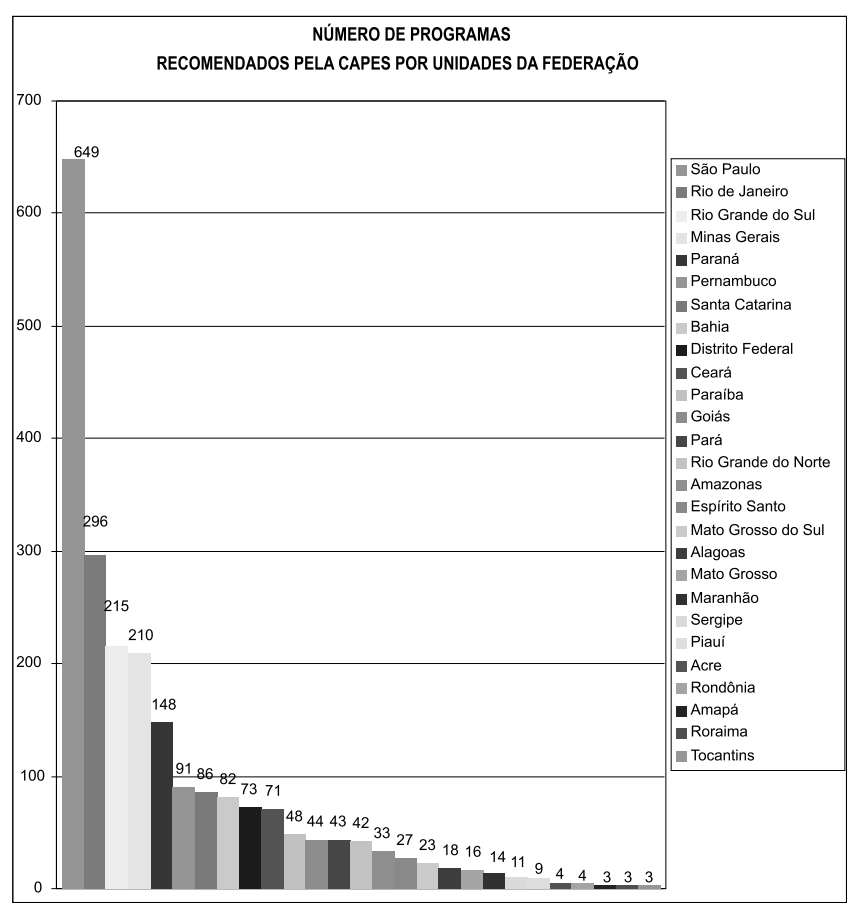

Fonte: CAPES - Informações tiradas da Avaliação Trienal 2007.

Gráfico 2 - Número de programas recomendados pela Capes por unidades da Federação. 
Como pode ser observado no gráfico 1 , do total de 2.266, programas, a região Sudeste concentra 1.182, ou seja, o maior número dos programas recomendados pela Capes e avaliados no triênio 2007. Em seguida, em ordem decrescente, aparecem as regiões Sul com 449, Nordeste com 386, Centro-oeste com 156 e norte com 93.

O gráfico 2 mostra o número de programas nos estados e unidades da federação e onde há o maior número de concentração. Pode ser constatada a geração de conhecimento nos estado das regiões mais desenvolvidas do Brasil. Esse fato, entretanto, não deve excluir a preocupação com o desenvolvimento da pesquisa nas regiões menos desenvolvidas, já que sabemos que conhecimento é instrumento e meio de desenvolvimento tanto nacional quanto regional.

Sabemos que a qualificação docente para o ensino superior não é apenas uma demanda social e mercadológica, é uma exigência legal que pode ser observada tanto no artigo 52 da LDB, que estabelece o percentual mínimo de somente $1 / 3$ de professores titulados ou com formação stricto sensu, quanto no artigo 207 da Constituição da Republica Federativa do Brasil que doutrinam sobre a indissociabilidade do ensino, da pesquisa e da extensão nas universidades. Mas nas regiões menos desenvolvidas do país, há poucos pesquisadores na maioria das instituições universitárias. Esse problema se agrava, ainda mais, pelo fato dessas instituições não conseguirem fixar doutores: por não possuírem infra-estrutura adequada ao desenvolvimento de pesquisa e/ou por não oferecerem salários que atraiam pesquisadores com experiências nos centros mais desenvolvidos.

Ressaltamos que, embora seja possível a existência de pesquisa sem pós-graduação instalada, não é possível a instalação da pós-graduação sem existência de pesquisa e de grupos de pesquisa nas instituições universitárias. Em outras palavras, a pesquisa precede a instalação de um programa de pós-graduação. É necessário, portanto, que nas regiões menos desenvolvidas, as universidades procurem agregar competências para criação, expansão e fortalecimento dos grupos de pesquisa.

A pesquisa, como sabemos, depende de pesquisadores com boa formação e de ambiente de trabalho que possa assegurar a esse pesquisadores con- dições mínimas de produtividade. As instituições das regiões menos desenvolvidas precisam, portanto, planejar a qualificação dos docentes ainda não qualificados, mas, principalmente, contratar docentes já qualificados e investir em infra-estrutura. Isso significa que o planejamento da pesquisa e o planejamento da pósgraduação não podem ser pensados e nem planejados separadamente.

A pós-graduação no Brasil é de caráter predominantemente disciplinar. Mas a necessidade está impondo a abertura para a criação de cursos de caráter interdisciplinar e multidisciplinar, como pode ser observado no gráfico 3, que indica o número de cursos das grandes áreas disciplinares e da grande área multidisciplinar já existente:

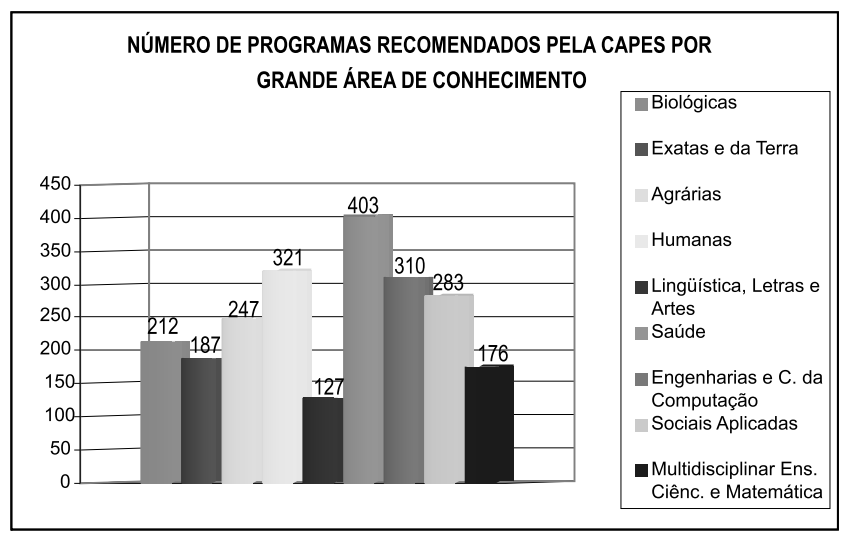

Fonte: CAPES Avaliação Trienal 2007.

Gráfico 3 - Número de Programas recomendados pela CAPES por Grande Área de Conhecimento.

O avanço da pós-graduação no Brasil, nesses quarenta anos, é incontestável. Mas é importante ressaltar que o desenvolvimento das regiões e estados menos desenvolvidos dependem de as universidades dessas regiões criarem as condições para implementar programas de pós-graduação de caráter tanto disciplinar quanto multidisciplinar, voltados para as suas vocações institucionais e regionais.

\section{Pós-graduação Strictu Sensu, desenvolvimento regional e mestrado em memória: linguagem e sociedade}

Com a finalidade de organizar a pesquisa 
institucionalizada e criar um curso de pós-graduação Stricto Sensu de caráter multidisciplinar na Universidade Estadual do Sudoeste da Bahia (Uesb), instituição de extrema importância para toda a região Sudoeste da Bahia e para parte da região do Norte de Minas Gerais, regiões em que tem exercido forte influência no desenvolvimento econômico e social, alguns pesquisadores, entendendo as pressões que colocam enormes desafios à Instituição e ao corpo docente qualificado para ampliar e consolidar a pesquisa na Uesb, reuniram-se e levantaram algumas questões:

a) Quais as necessidades sociais e tecnológicas da região do Sudoeste da Bahia e do Estado da Bahia?

b) Quais as potencialidades existente na Universidade Estadual do Sudoeste da Bahia?

c) Em que áreas estratégicas a universidade precisa avançar?

d) Que grau de excelência a universidade precisa alcançar?

e) Que interações e parcerias podem ser construídas?

As respostas a estas questões foram fundamentais para a construção do Projeto do Mestrado em Memória: Linguagem e Sociedade.

Entendendo que a perspectiva multidisciplinar é um meio de superar os limites correspondentes às fronteiras tradicionalmente estabelecidas nas instituições acadêmicas em torno das disciplinas, na direção de uma cooperação efetiva de profissionais capacitados em diversos âmbitos do saber, e que a temática da Memória é por si só eminentemente multidisciplinar, criou-se, em 2005, o curso de Especialização em Educação, Cultura e Memória, com uma estrutura multidisciplinar, para atender a uma demanda de qualificação de profissionais de diferentes áreas, tais como: Educação, Sociologia, Antropologia, História, Direito, Comunicação, Letras, entre outras.

A execução do curso para a primeira turma indicou a maneira como memória e multidisciplinaridade se entrecruzam. Em razão da sua multifacialidade como fenômeno, a compreensão da memória como objeto ou meio pelo qual se ultrapassa impasses analíticos no estudo de outros objetos é incontornável, dado a sua intersecção com diversos saberes.
Como conseqüência, a fim de responder às demandas do mercado regional com profissionais dotados de competência teórico-prática e em condições de exercer bem seu papel na sociedade, pesquisadores dos grupos de pesquisa cadastrados no CNPq e autorizados pela Uesb - Grupo de Pesquisa Museu Pedagógico: Educação Escolar, Grupo de Pesquisa Museu Pedagógico: Educação Não-Escolar, Grupo de Pesquisa Cultura, Memória e Desenvolvimento, Grupo de Pesquisa em Estudos Lingüísticos, Grupo de Pesquisa em Análise de Discurso, Grupo de Pesquisa Literatura e História Social e Grupo de Pesquisa Teoria e História Literária - acentuaram esforços para uma prática conjunta fundada nos princípios de formação multidisciplinar para a pesquisa, de modo a consolidar e a revitalizar permanentemente o conhecimento, frente aos novos desafios sobre temas interdisciplinares que exigem a presença indispensável de teorias relativas à memória, linguagem e sociedade.

A evolução técnico-científica dos grupos de pesquisa que agregam docentes que atuam numa perspectiva multidisciplinar, ligados a diferentes áreas nas suas ações de ensino, pesquisa, apontava para um corpo de professores pesquisadores que reunia conhecimentos capazes de articular a temática em torno da memória, linguagem e sociedade.

Em decorrência de encontros e diálogos, iniciados no início de 2005 e acentuados durante o ano de 2006 e início de 2007, e como prolongamento das atividades acadêmicas e dos projetos de pesquisa dos docentes-pesquisadores desses grupos, foi criada uma plataforma intelectual e institucional comum para elaborar a proposta do Curso de Pós-Graduação Stricto Sensu em Memória: Linguagem e Sociedade, nível de Mestrado, com área de concentração em: Multidisciplinaridade da Memória e, inicialmente, com duas linhas de pesquisa, quais sejam: a) Memória, Cultura e Educação; b) e Memória, Discursos e Narrativas, como campos de investigação e problematização da memória, linguagem e sociedade, privilegiando a perspectiva teórico-epistemológica e a análise crítica. A proposta do Curso foi avaliada, aprovada e recomendada pelo Comitê Técnico Científico -CTC- da CAPES, que lhe atribui a nota 4, em julho de 2007.

O mestrado em Memória: Linguagem e Socie- 
dade tem início, em março de 2008, com um quadro de docentes permanentes constituído por onze professores doutores, sendo três da área de Educação, um da área de Lingüística, um da área de Literatura Brasileira; dois da área de Teoria Literária; dois da área de História; um da área de Antropologia; e um da área de Sociologia. Além disso, contará, inicialmente, com três professores doutores colaboradores: dois da área de Lingüística e um da área de Sociologia.

Entendendo a importância da proposta e visando a contribuir com a área multidisciplinar de conhecimento aqui eleita e, ao mesmo tempo, com a elucidação de problemas que a área impõe, a Uesb, ciente do seu papel frente à sua inserção no Estado da Bahia e entorno regional, vem tentando agregar esforços dos grupos de pesquisa e, conseqüentemente, de seus pesquisadores, na perspectiva de contribuir, cada vez mais, com o desenvolvimento da Região do Sudoeste da Bahia, além de outras regiões do Estado e boa parte do norte de Minas. Dessa forma, tanto o quadro de professores permanentes quanto o quadro de professores colaboradores serão ampliados, à medida que outros pesquisadores da instituição se adequarem às exigências da CAPES, o que possibilitará o aumento de número de vagas para atender a grande demanda regional e à criação do Doutorado na área.

\section{Considerações finais}

Entendendo a importância da pós-graduação stricto sensu no desenvolvimento regional, o Curso de Mestrado em Memória: Linguagem e Sociedade se insere no plano de desenvolvimento regional da Uesb, que, juntamente com os pesquisadores dos grupos de pesquisa estabelecidos, tem se empenhado na reflexão e proposição de projetos de formação, sintonizados com as reais necessidades colocadas pela demanda imposta pela região do Sudoeste da Bahia.

Esse curso, ao lado de outros programas já existentes na instituição, possibilitará o fortalecimento e ampliação do intercâmbio entre a Uesb e outras instituições de ensino e pesquisa, inserindo, de forma significativa, os profissionais envolvidos e contribuindo para a otimização de pesquisas que visam a contribuir com o desenvolvimento regional.

\section{REFERÊNCIAS}

BARROS, Elionora Maria Cavalcanti de Barros. Política de Pós-Graduação: um estudo da comunidade científica. São Carlos: Ed. UFSCar, 1998.

CAPES - www.capes.gov.br, acesso em dezembro de 2007.

CNPq - www.cnpq.br, acesso em dezembro de 2007.

FERREIRA, Marieta de Moraes; MOREIRA, Regina da Luz. Capes, 50 Anos. Rio de Janeiro: CPDOC/FGV e Capes, 2001.

SBPC - www.sbpcnet.org.br, acesso em dezembro de 2007.

SUCUPIRA, Newton. Definição dos Cursos de Pós-Graduação. Revista Brasileira de Estudos Pedagógicos, Brasília: v. 44, n. 100, p. 413 - 431, out./dez., 1965. 